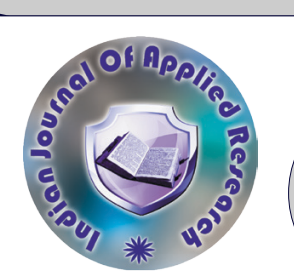

General Surgery

\title{
COLOPLASTY: AN ALTERNATIVE TO GASTRIC PULL-UP IN BENIGN DISEASES OF ESOPHAGUS
}

\author{
Dr. Nitin R \\ Nangare \\ Dr. Dhairyashil B \\ Patil* \\ Associate Professor, Department Of General Surgery, Krishna Institute Of Medical \\ Sciences, Karad
}

\section{ABSTRACT}

Restoration of swallowing in a patient with dysphagia due to nondilatable corrosive stricture of esophagus remains a surgical challenge. Organs available for replacement are stomach, jejunum, or colon. Jejunum is useful to replace a small segment, whereas stomach and colon are required for a long-segment replacement. In cases where the stomach is also injured, colon remains the only option. The route of colonic interposition has also been a subject of debate over the years. The choice of the colon as an esophageal substitute results primarily from the unavailability of the stomach. However, given its durability and function, colon interposition keeps elective indications in patients with benign or malignant esophageal disease who are potential candidates for long survival. The choice of the colonic portion used for esophageal reconstruction depends on the required length of the graft, and the encountered colonic vascular anatomy, the last being characterized by the near-invariability of the left colonic vessels, in contrast to the vascular pattern of the right side of the colon. Accordingly, the transverse colon with all or part of the ascending colon is the substitute of choice, positioned in the isoperistaltic direction, and supplied either from the left colic vessels for long grafts or middle colic vessels for shorter grafts. Technical key points are: full mobilization of the entire colon, identification of the main colonic vessels and collaterals, and a prolonged clamping test to ensure the permeability of the chosen nourishing pedicle. Transposition through the posterior mediastinum in the esophageal bed is the shortest one and thereby offers the best functional results. When the esophageal bed is not available, the retrosternal route is the preferred alternative option. The food bolus traveling mainly by gravity makes straightness of the conduit of paramount importance. The proximal anastomosis is a single-layer hand-fashioned endto-end anastomosis to prevent narrowing. When the stomach is available, the distal anastomosis is best performed at the posterior part of the antrum for the reasons of pedicle positioning and reflux prevention, and a gastric drainage procedure is added when the esophagus and vagus nerves have been removed. In the other cases, a Roux-en-Y jejunal loop is preferable to prevent bile reflux into the colon. To construct a colon interposition graft that is long enough, we examined a procedure in which the colon is transected proximally at the site of the cecum and the right colic artery is transected, in addition to ligation of the middle artery. Here we examined the series of 20 procedures for post-corrosive esophageal strictures treated with retrosternal colonic interpositions.

\section{KEYWORDS : Esophageal Surgery; Colon Interposition; Esophageal Cancer; Esophageal Motility Dysfunction; Benign} Esophageal Disease

\section{INTRODUCTION-}

Colon interposition has been used since the beginning of the $20^{\text {th }}$ century as a substitute for esophageal replacement. Colon interposition is mainly chosen as a second line treatment when the stomach cannot be used, when the stomach has to be resected for oncological or technical reasons, or when the stomach is deliberately kept intact for benign diseases in young patients with long-life expectancy. During the surgery the vascularization of the colon must be carefully assessed, as well as the type of the graft (right or left colon), the length of the graft, the surgical approach and the route of the reconstruction. Early complications such as graft necrosis or anastomotic leaks, and late complications such as redundancy depend on the quality of the initial surgery. Despite a complex and time-consuming procedure requiring at least three or four digestive anastomoses, reported long term functional outcomes of colon interposition are good, with an acceptable operative risk. Thus, in much selected indications, colon interposition could be seen as a valuable alternative for esophageal replacement when stomach cannot be considered.

Inability to swallow following a corrosive stricture of the esophagus is one of the most distressing symptoms that patients experience. Treatment of these benign esophageal strictures following corrosive ingestion has remained a challenge. The treatment options include dilatations (blind, retrograde endless string, and endoscopic) or creating a new passage (replacement). While endoscopic dilatations are meant for patients with short-length strictures, long or multiple strictures require surgical intervention in some form or the other in the long run. Among the jejunal interposition, use of gastric or reversed gastric tube and colonic interposition, the result of the use of colon as the organ for replacement has been found to be satisfactory in most studies. Controversy exists as to the route of colonic graft placement - antesternal, retrosternal, and esophageal bed.

\section{MATERIALS AND METHODS-}

A total 20 patients were operated for retrosternal esophageal coloplasty during the period of January 2018 to December 2019 in Department of surgery,Krishna Institute of Medical Sciences, karad.
All the patients were diagnosed with benign esophageal stricture due to corrosive injuries. None of the patients had malignant change in the esophagus.

\section{SURGICAL TECHNIQUE}

In all patients, we constructed a long colon graft supplied exclusively by the inferior mesenteric artery. Initially, we mobilized the ascending colon, the right flexure, and the transverse colon. Using transillumination, we then clamped the middle colic artery, the right colic artery, and the connection between the ileocolic and right colic artery temporarily using vascular clamps. In this situation, only the inferior mesenteric artery feeds the ascending and transverse colon. If blood supply remained adequate after prolonged trial clamping, we started constructing the long colonic interposition graft. The right and middle colic arteries were divided and ligated as centrally as possible. Then we transected the remaining mesentery of the right colon up to the level of the transverse colon. By transecting the ascending colon just above the cecum, we obtained a fairly long and mobile colon graft that could be passed easily up into the thorax and to the cervical region. We did not mobilize the left flexure and the descending colon, and we did not identify the left colic artery and the branching ascending arteries of the left flexure. Distal transection of the colon was not performed at this stage of the procedure.

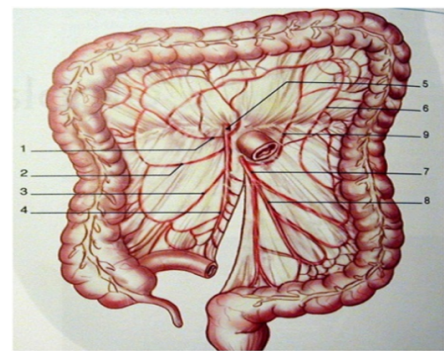

We brought the colon up to the cervical region through retrosternal cave created by an opening in the diaphragm. Then we performed the 
cervical anastomosis using a modified two-layer end-to-end technique. After pull-through of the colonic graft, we constructed the anastomosis between the stomach and the colon to reconstruct the passage in the 20 patients. We transected the colon, which descended from inside the thorax into the abdomen, in front of the stomach and constructed an end-to-side anastomosis between the colon and the stomach. Reconstruction was completed by connecting the cecum to the transverse colon by an end-to-end anastomosis. The expanded colon interposition graft was then attached to the hiatus esophageus using several single-stitch sutures to prevent an elongation of the graft inside the thorax. If present, the remaining stomach was fixed to the diaphragm to avoid passage of the stomach into the thorax.

\section{RESULTS}

In all patients in whom we planned an esophageal reconstruction with a modified colonic interposition graft, we could create such a graft. In no patient did we have to change the reconstructive procedure because of insufficient intraoperative blood supply. During routine postoperative surveillance (endoscopy), we observed sufficient blood supply to the graft in all patients.

No complications resulted from insufficient blood supply or insufficient venous drainage. Minor complications (pneumonia without respiratory insufficiency) occurred in three patients. In two of these patients, the cause of the pulmonary inflammation was recurrent microaspiration of oral nutrients. Major complications were found four times: two anastamotic leaks(minor), two developed deep vein thrombosis and one case of pneumonia, which was complicated by a septic state and respiratory insufficiency. The latter patient subsequently died, resulting in sigle mortality in this case series. The cause of death was pneumonia with septicaemia. The anastomotic leakage, found in two patient, was evident on the fifth postoperative day through neck incision, which was managed conservatively as it was minor leak. Oral nutrient intake was not delayed. All the patients were covered with feeding jejunostomy for the nutritional support. The average duration of postoperative artificial ventilatory support was $2 \pm 1.5$ days; eight patients were extubated immediately after surgery. Length of stay on the intensive care unit averaged 5-7 days. The total hospital stay averaged 16-20 days with an exception of death.

\section{DISCUSSION}

Almost a century ago, Kelling and Vuillet introduced the use of the colon as an esophageal substitute. Since then, several modifications to this approach have been described, using the left, the right, or the transverse colon as an interposition graft. Interposition of the left colon became the most popular procedure. It requires wide mobilization of the entire colon, ligation of the middle colic artery, and transection of the colon at the right flexure and somewhere between the left flexure and the midportion of the descending colon, depending on the patient's anatomy. This preference for left colic interposition is based on the vascular anatomy and its natural variation in the colon. According to several autopsy studies, the arterial anastomoses (marginal artery) between the ileocolic and right colic vessels are absent in up to $70 \%$ of patients, whereas the collaterals between the left and right colic artery are mostly sufficient. Corresponding differences can be found with venous collaterals in the colon. In the left colon, the marginal venous anastomoses are excellent, but ileocolic venous collaterals are insufficient in $20 \%$ to $30 \%$ of patients. In patients scheduled for colonic interposition, a discontinuity of the superior-inferior mesenteric artery anastomosis at the left flexure was seen in $48 \%$; discontinuity of the marginal artery between the middle and right colic artery was seen in $70 \%$. However, the relevance of these angiography findings for the selection of the colon graft is questionable: intraoperative trial clamping rarely demonstrates an inadequate collateral flow through arterial anastomoses at the splenic flexure. Clinical results appear to support the superiority of left to right colonic interposition. A combined evaluation of studies that allow a separate analysis of left or right colon grafts revealed a rate of colon necrosis or ischemia of $4.6 \%(20 / 438)$ with use of the left colon and of $10.8 \%$ $(13 / 120)$ with use of the right. However, even an almost $5 \%$ rate of left colonic graft failure cannot be considered optimal, because this complication is potentially life-threatening and adds to the significant general risk of the procedure. A possible reason for ischemic graft failure may be the preparation and mobilization of the left colonic flexure. This step is part of the standard procedure to obtain a left colon interposition graft, but it may damage the ascending branch of the left colic artery or the marginal arteries and veins at this site. To minimize this risk, we modified the conventional technique. If the left flexure is not to be touched, the ascending colon must be included into the graft to obtain sufficient graft length. For this step, the middle and right colic arteries and the collaterals from the ileocolic artery must be ligated. A similar procedure was originally described in two patients by Lees to create a particularly long colon graft. However, a larger series by Osborne et al revealed a graft-related complication rate of $35 \%$ when the ascending colon was part of a graft supplied by the left colic artery. In the latter report, the complete colon, including the splenic flexure, was mobilized. Based on our preliminary results, this complication rate appears to be significantly improved if the splenic flexure remains untouched. Intraoperative temporary clamping demonstrated in each case that arterial blood supply and venous drainage, even of the proximal parts of the colon by the left colic artery and vein, were adequate. This potent collateral circulation allows creation of a long colon graft that primarily includes the ascending and the transverse colon, eliminating the need to mobilize the left flexure to move the graft up to the cervical region. The cervical anastomosis between the esophagus and the colon interposition graft can usually be created easily because there is little tension between the fixed left colonic flexure and the proximal end of the graft. The second advantage of our method is that the distal anastomosis of the graft can be performed later at a variable site and can, therefore, be adjusted exactly to the patient's anatomy. To complete the reconstruction, we transected the transverse colon at the site where we wanted to perform the anastomosis between the colon and the stomach or small bowel. Finally, the cecum was connected to the transverse colon. It should be noted that the individual anatomy of the colic vasculature may sometimes prevent use of the whole right colon or of its most proximal portion as an interposition graft. Thus, in a few patients, multiple middle colic arteries are present with marginal arteries missing at this site or venous collaterals are absent between the ascending and transverse colon. However, such rare anatomic variations should be identified easily during intraoperative preparation and trial clamping. With our technique, the frequency of major complications was $27 \%$ and that of anastomotic leakage was $7 \%$. Postoperative graft perfusion was excellent in each patient. Two risk factors may have contributed to the postoperative complications and the one death.

Despite the above limitations, the results of our series suggest that the described modifications represent an alternative to established procedures for creating a colon interposition graft. Our method may be particularly helpful when a long colonic interposition graft is required. Also Proper selection of patients is much more important in such operative interventions.

\section{REFERENCES-}

Rice TW. Colon replacement. In: Pearson FG, Deslauriers J, Ginsberg RJ, et al, eds. Esophageal surgery. New York: Churchill Livingstone; 1995:761-774.

2. Hiebert CA, Bredenberg CE. Selection and placement of conduits. In: Pearson FG, Deslauriers J, Ginsberg RJ, et al, eds. Esophageal surgery. New York: Churchill Livingstone; 1995:649-656.

3. Sonneland J, Anson BJ, Beaton LE. Surgical anatomy of the arterial supply to the colon from the superior mesenteric artery based upon a study of 600 specimen. Surg Gynecol Obstet 1958;106:385-398.

4. Schardey HM, Joosten U, Finke U, et al. The prevention of anastomotic leakage after total gastrectomy with local decontamination. Ann Surg 1997; 225:172-180

5. Kelling GE. Oesophagoplastik mit Hilfe des Querkolons. Zentralbl Chir 1911; 38:1209 Kelling -1212 .

6. Vuillet H. De l'oesophagoplastie et des diverses modifications. Semin Med 1911; 31:529-534.

De Meester TR, Johansson KE, Franze J, et al. Indications, surgical technique, and longterm functional results of colon interposition or bypass. Ann Surg 1988; 208:460-474.

8. Beck AR, Baronofsky ID. A study of the left colon as a replacement for the resected esophagus. Surgery 1960;48:499-509.

9. Kralik J, Turek K. Die Wichtigkeit des veno"sen Abflusses aus dem zur O sophagoplastik verwendeten Kolontransplantat. Zentralbl Chir 1967; 44:2772-2776.

10. Nicks R. Colonic replacement of the oesophagus. Some observations on infarction and Nicks R. Colonic replacement of the oesoph
wound leakage. Br J Surg 1967;54:124-128.

11. Peters JH, Kronson JW, Katz M, DeMeester TR. Arterial anatomic considerations in colon interposition for esophageal replacement. Arch Surg 1995;130:858-863.

12. Ventemiglia R, Khalil KG, Frazier OH, Mountain CF. The role of preoperative mesenteric arteriography in colon interposition. J Thorac Cardiovasc Surg 1977; 74:98 $-104$

13. Belsey R. Reconstruction of the esophagus with left colon. J Thorac Cardiovasc Surg 1965; 49:33-53.

14. Glasgow JC, Cannon JP, Elkins RC. Colon interposition for benign esophageal disease. Am J Surg 1979; 137:175-179. Vol. 231 c No. 2 Colon Interposition for Esophageal Replacement

15. Wilkins EW, Jr. Long-segment colon substitution for the esophagus. Ann Surg 1980 192:722-725.

16. Keenan DJM, Hamilton JRL, Gibbons J, Stevenson HM. Surgery for benign esophagea stricture. J Thorac Cardiovasc Surg 1984; 88:182-188.

17. Curet-Scott MJ, Ferguson MK, Little AG, Skinner DB. Colon interposition for benign esophageal disease. Surgery 1987; 102:568-574.

18. Cerfolio RJ, Allen MS, Deschamps C, Trtastek VF, Pairolero PC. Esophageal replacement by colon interposition. Ann Thorac Surg 1995; 59:1382-1384.

19. Mansour KA, Bryan FC, Carlson GW. Bowel interposition for esophageal replacement: twenty-five-year experience. Ann Thorac Surg 1997; 64:752-756.

20. Wain JC, Wright CD, Kuo EY, et al. Long-segment colon interposition for acquired 
esophageal disease. Ann Thorac Surg 1999;67:313-318.

21. Lees W. Colonic replacement after pharyngolaryngectomy. Br J Surg 1967; 54:541-547.

22. Osborne MP, Griffiths JD, Shaw HJ. Colon transposition in the management of upper gastrointestinal cancer. Cancer 1982; 50:2235-2242.

23. Siewert JR, Bartels H, Bollschweiler E, et al. Plattenepithelcarcinom des O" sophagus. Chirurgie 1992; 63:693-700

24. Bartels H, Stein HJ, Siewert JR. Preoperative risk analysis and postoperative mortality of oesophagectomy for resectable oesophageal cancer. Br J Surg 1998; 85:840-848.

25. Buntain WL, Payne WS, Lynn HB. Esophageal reconstruction for benign disease: a long-term appraisal. Am Surg 1980; 46:67-79.

26. Mansour KA, Hansen HA, Hersh T, Miller JI Jr, Hatcher CR Jr. Colon interposition for advanced nonmalignant esophageal stricture: experience with 40 patients. Ann Thorac Surg 1981;32:584-591.

27. Cherveniakov A, Cherveniakov P. Colon substitution for radical treatment of cardia and lower third esophageal cancer. Eur J Cardiothorac Surg 1993; 7:601-605.

28. Negre J, Markkula H. Esophagectomy and colon interposition for benign esophageal stricture. Acta Chir Scand 1984; 150:639-642.

29. Thomas P, Fuentes P, Giudicelli R, Reboud E. Colon interposition for esophageal Thomas P, Fuentes P, Giudicili R, Reboud E. Colon interposition for esophageal
replacement: current indications and long-term function. Ann Thorac Surg 1997; 64:757-764. 